\title{
Development of Pneumatic Aerodynamic Devices to Improve the Performance, Economics, and Safety of Heavy Vehicles
}

Robert J. Englar Georgia Tech Research Institute 
SAE routinely stocks printed papers for a period of three years following date of publication. Direct your orders to SAE Customer Sales and Satisfaction Department.

Quantity reprint rates can be obtained from the Customer Sales and Satisfaction Department.

To request permission to reprint a technical paper or permission to use copyrighted SAE publications in other works, contact the SAE Publications Group.

This article was prepared as an account of work sponsored by an agency of the United States

Government. Neither the United States Government nor any agency thereof, nor any of their employees, makes any warranty, express or implied, or assumes any legal liability or responsibility for the accuracy, completeness, or usefulness of any information, apparatus, product, or process disclosed, or represents that its use would not infringe privately owned rights. Reference herein to any specific commercial product, process, or service by trade name, trademark, manufacturer, or otherwise does not necessarily constitute or imply its endorsement, recommendation, or favoring by the United States Government or any agency thereof. The views and opinions of authors expressed herein do not necessarily state or reflect those of the United States Government or any agency thereof.

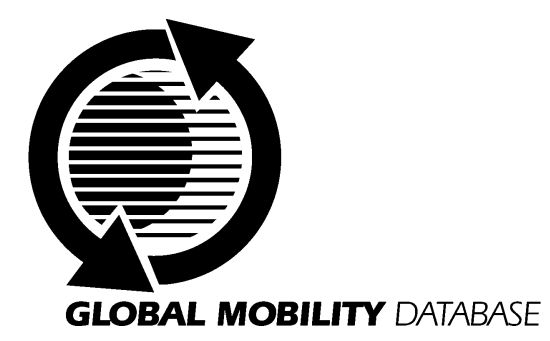

All SAE papers, standards, and selected books are abstracted and indexed in the Global Mobility Database

ISSN 0148-7191

No copyright is asserted in the works of U.S. Government employees.

Positions and opinions advanced in this paper are those of the author(s) and not necessarily those of SAE. The author is solely responsible for the content of the paper. A process is available by which discussions will be printed with the paper if it is published in SAE Transactions. For permission to publish this paper in full or in part, contact the SAE Publications Group.

Persons wishing to submit papers to be considered for presentation or publication through SAE should send the manuscript or a 300 word abstract of a proposed manuscript to: Secretary, Engineering Meetings Board, SAE.

\section{Printed in USA}




\title{
Development of Pneumatic Aerodynamic Devices to Improve the Performance, Economics, and Safety of Heavy Vehicles
}

\author{
Robert J. Englar \\ Georgia Tech Research Institute
}

No copyright is asserted in the works of U.S. Government employees

\begin{abstract}
Under contract to the DOE Office of Heavy Vehicle Technologies, the Georgia Tech Research Institute (GTRI) is developing and evaluating pneumatic (blown) aerodynamic devices to improve the performance, economics, stability and safety of operation of Heavy Vehicles. The objective of this program is to apply the pneumatic aerodynamic aircraft technology previously developed and flight-tested by GTRI personnel to the design of an efficient blown tractor-trailer configuration. Recent experimental results obtained by GTRI using blowing have shown drag reductions of $35 \%$ on a streamlined automobile wind-tunnel model. Also measured were lift or download increases of $100-150 \%$ and the ability to control aerodynamic moments about all 3 axes without any moving control surfaces. Similar drag reductions yielded by blowing on bluff afterbody trailers in current US trucking fleet operations are anticipated to reduce yearly fuel consumption by more than 1.2 billion gallons, while even further reduction is possible using pneumatic lift to reduce tire rolling resistance. Conversely, increased drag and down force generated instantaneously by blowing can greatly increase braking characteristics and control in wet/icy weather due to effective "weight" increases on the tires. Safety is also enhanced by controlling side loads and moments caused on these Heavy Vehicles by winds, gusts and other vehicles passing. This may also help to eliminate the jack-knifing problem if caused by extreme wind side loads on the trailer. Lastly, reduction of the turbulent wake behind the trailer can reduce splash and spray patterns and rough air being experienced by following vehicles. To be presented by GTRI in this paper will be results developed during the early portion of this effort, including a preliminary systems study, CFD prediction of the blown flowfields, and design of the baseline conventional tractor-trailer model and the pneumatic wind-tunnel model.
\end{abstract}

\section{INTRODUCTION}

Users of heavy trucks (such as tractor/trailer combination vehicles) contend with a number of less than optimum operating circumstances. These vehicles, despite significant reductions in drag coefficients in the latest generation of tractors, remain "draggy" compared to much more streamlined automobiles. This is due, in part, to practical limitations on: physically providing a smooth aft surface such as a boat tail to prevent flow separation and turbulence at the rear of the trailer; completely sealing the gap between the tractor and the trailer; and sealing the underbody of the vehicles. In addition, there may yet be drag reductions possible from further investigations into cooling drag. Typical drag coefficient values for a variety of commercial vehicles are shown in Figure 1 (from Reference 1, 1990), which also shows the significant fuel savings that can result if the drag coefficient can be reduced. It has been estimated by personnel of the American Trucking Associations (ATA) that, applied to today's US heavy vehicle fleet only, these drag reductions approaching $35 \%$ could result in roughly 1.2 billion gallons of fuel saved per year.

Another result of aerodynamically "dirty" vehicles is the production of splash and spray, a nuisance to motorists and truck drivers alike, as well as turbulence in the vicinity of large vehicles, which is disturbing to passenger car drivers. These shortcomings are explained further in the ATA Statement of Need for Improved Heavy Truck Aerodynamics, Reference 2.

Considerable recent interest has arisen in a number of quarters in techniques to reduce Heavy Vehicle drag coefficients to improve highway operating efficiency, primarily because the drag force rises with the square of the vehicle velocity and the required horsepower to overcome it increases with the cube of the truck's velocity. With fuel prices rising dramatically in 1999-2000, drag 
reduction is thus a vital concern to the trucking industry. However, there is significant reason to believe that appreciable additional gains can be had by careful control of aerodynamic forces and moments other than drag, which for the most part have been ignored in current truck design and operation. For instance, the creation of lift on the vehicle (effective weight reduction) can unload the tires and reduce rolling resistance, while creation of negative lift or downforce can increase weight on wheels and traction, thus increasing braking as well as handling in wet/icy weather. While Figure 2 shows that drag increases greatly due to side wind (yaw angle), it also implies increased side force and yawing moment on the trailer, thus reducing its directional stability and safety. Lastly, there are instances where additional drag increase is desirable, such as steep downhill operations in mountains, or sudden need for emergency braking from high speed.

Unfortunately, development of aerodynamic devices to this point has been mainly centered on drag reduction, and those devices that do so, such as boattails, frequently encounter operational problems such as excessive length and interference at loading docks. It would be quite desirable to develop aerodynamic devices that could accomplish two or more of the above potential gains while requiring little mechanical restriction or impact on vehicle operation. Recent aerodynamic research (Reference 3) at the Georgia Tech Research Institute (GTRI) Aerospace, Transportation and Advanced Systems Laboratory has identified significant reductions and/or augmentations of vehicle forces and moments which can be achieved on automotive vehicles by the use of tangential injection of pressurized air into the vehicle's boundary layer, thus strongly modifying the aerodynamic flowfield around that vehicle. Since blowing/momentum injection can affect the vehicle's aerody- namic lift, drag, and side force as well as aerodynamic moments, the impact of blowing on the aerodynamic performance, safety, economics and stability appears to offer significant improvements in Heavy Vehicle operation. These potential gains have led to a current research program (Ref.4) being conducted at GTRI for the DOE Office of Heavy Vehicle Technologies. This program includes use of appropriate analytical codes for pneumatic configuration design; experimental wind-tunnel evaluation of this blown concept and a representative baseline tractortrailer; analysis of the resulting data; and transfer of the technology to the Heavy Vehicle industry for the development of a full-scale road-test demonstrator. Anticipated overall results to be confirmed will be the pneumatic augmentation or reduction of aerodynamic forces and moments as desired by the vehicle's driver or automated control system, and the resulting increased performance, economics, stability, and safety of that vehicle's operation. Geometry and blowing system requirements for these devices are being determined, and a preliminary systems study is being conducted. This pneumatic model will include devices to: reduce aerodynamic drag for efficiency or increase drag for braking; increase lift (and thus reduce tire rolling resistance) or reduce lift (and thus increase traction and braking); and provide increased lateral/directional stability and safety, all without use of external moving aerodynamic components. The present paper will describe the basis of pneumatic aerodynamics as applied to air vehicles, the application to a streamlined automobile configuration, and accomplishments to date on this current DOE program for Heavy Vehicles, including the initial feasibility study and design of the pneumatic wind-tunnel model which will eventually lead to an on-the-road test demonstrator device.
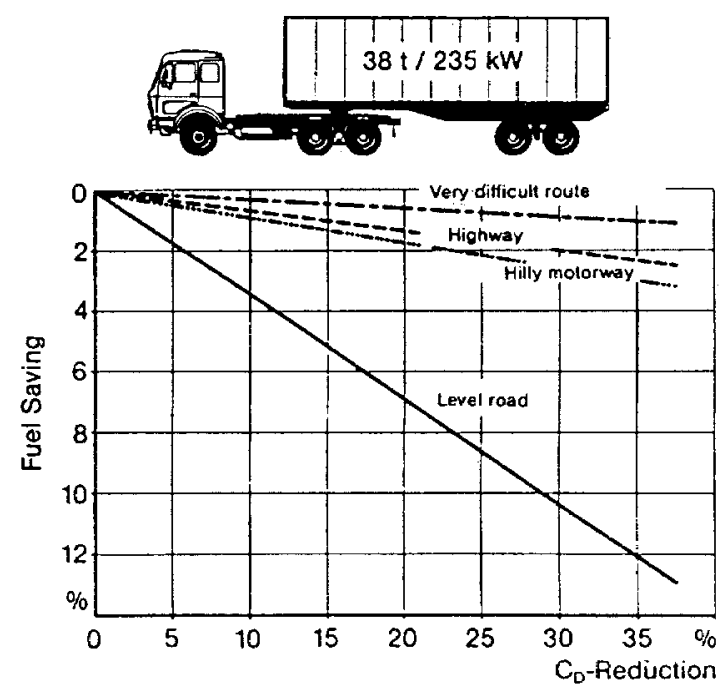

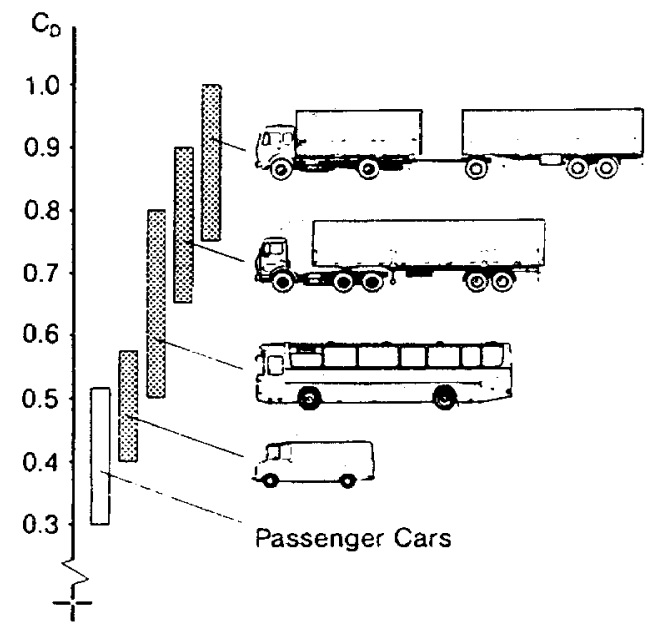

Drag coefficients of different commercial vehicles

Influence of drag on fuel consumption of a 38-tonne semitrailer

Figure 1. Typical Vehicle Drag Coefficients and Effects on Fuel Consumption (from Ref. 1) 


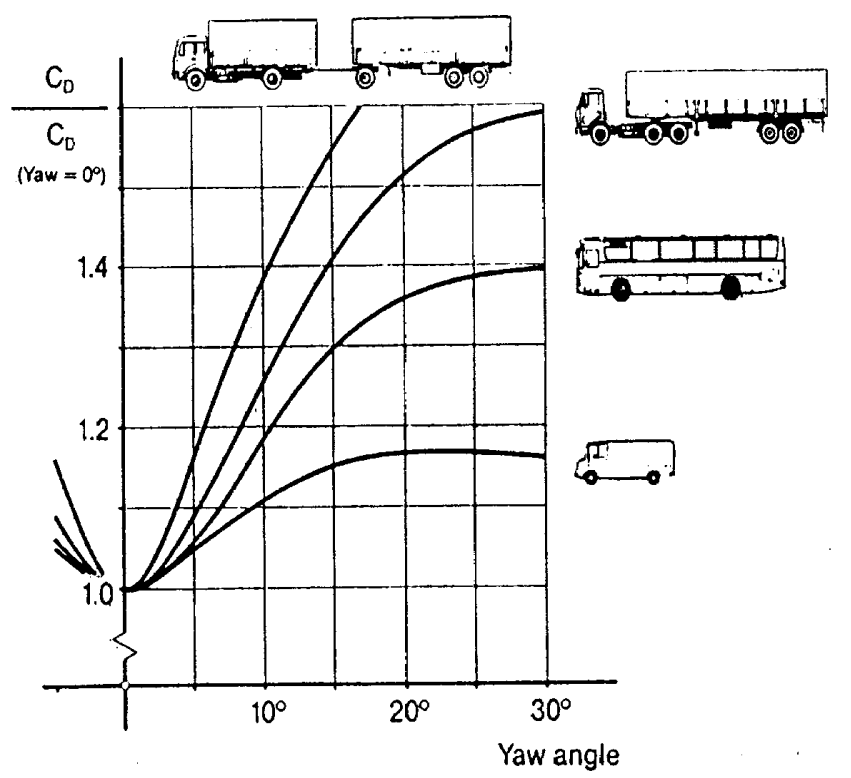

Drag versus yaw of different vehicle types

Figure 2. Vehicle Directional Sensitivity to Side Winds, from Ref. 1

\section{PNEUMATIC AERODYNAMICS}

GTRI researchers have been involved for a number of years in the development of pneumatic (pressurized air blowing) concepts to yield efficient yet mechanically simple means to control and augment or reduce the aerodynamic forces and moments acting on aircraft, both fixed wing and rotary wing (References 5, 6 and 7 for example). Figure 3 shows the basic pneumatic concept, which has become known as Circulation Control (CC) aerodynamics. Here, the conventional mechanical trailing edge flap, aileron or rudder has been replaced with a fixed curved surface with a tangential slot ejecting a jet sheet over that surface. That jet remains attached to that curved surface by a balance between sub-ambient static pressure on the surface and centrifugal force (the socalled Coanda effect, Reference 5). This greatly entrains the external flowfield to follow the jet, and thus enhances the circulation around the airfoil and the aerodynamic forces produced by it. The governing parameter is not angle of attack, but rather the blowing momentum coefficient:

$$
\mathrm{C}_{\mu}=\dot{\mathrm{m}} \mathrm{V}_{\mathrm{j}} / \text { ( } \mathrm{q} \mathrm{c} \text { ) }
$$

where $\dot{m}$ is the jet mass flow, $V_{j}$ the isentropic jet velocity, $\mathrm{C}$ is a reference wing chord (or area for a 3-D configuration) and $q$ is the freestream dynamic pressure $=0.5 \rho V^{2}$, with $\rho$ being the freestream density, not jet density.
Figure 4 shows two very simple blown airfoil sections which were employed as pneumatic helicopter non-pitching rotor blades (Reference 5). Here lift coefficient is plotted as a function of the blowing coefficient $\mathrm{C}_{\mu}$, all at $\alpha=0^{\circ}$ angle of attack. Note the very high lift generated, but more importantly, the slope of the lift versus blowing curves. At lower blowing coefficient values, augmentation of the aerodynamic lift by a factor of $\Delta \mathrm{C}_{\mid} / \mathrm{C}_{\mu}=80$ is recorded, representing an $8000 \%$ return on the invested momentum (which in a physical sense is also equal to the jet thrust). Familiarity with blown systems will remind the reader that this is quite extraordinary; thrust-deflecting VTOL aircraft are fortunate if they recover anything near $100 \%$ of the thrust expended for vertical lift. It is because of this high return, or conversely, because of very low required blowing input and associated power required to achieve a desired lift, that Circulation Control airfoils appear very promising for a number of applications. In addition to full-scale flight on a CC Rotor vehicle (Reference 5), they were also employed on the A-6/CC Wing Short Take Off \& Landing (STOL) flight demonstrator aircraft, Figure 5 and Reference 6 . This demonstration showed the STOL performance listed in this figure, but also suggested capabilities very useful to ground vehicles: in the short takeoff, it demonstrated high lift and reduced drag, while in the approach / landing, very high lift at high drag was shown. A more recent CCW airfoil, portions of which are quite applicable to Heavy Vehicles, is shown in Figure 6. This Dual-Radius CCW configuration has a very short-chord flap with a curved upper surface; this flap rotates about a smaller radius, but returns to zero deflection for low-drag cruise flight. The potential gains are shown in Figures 7 and 8 . In Figure 7, both flap angle and blowing are varied, and significant change in lift augmentation results. For reference, data for a mechanical single-slotted Fowler flap (where the flap deflects plus moves both aft and down) is also shown installed on the same baseline airfoil, yielding a $\mathrm{C}_{\mid}$of less than 2 at these conditions. In Figure 8, lift/drag values are plotted, with blowing, not angle of attack, varying along each CCW curve. Again for reference, the drag polar (lift vs drag) for the baseline clean airfoil with $0^{\circ}$ flaps is plotted, but the variable along this baseline curve is angle of attack, not blowing. Note that drag can be ether increased or decreased with blowing, while lift always increases. It is suggested by these results that certain of the higher flap deflections could be employed as aft aerodynamic surfaces on Heavy Vehicles. For negative lift or download, the blown surface would be inverted and installed on the lower surface of the vehicle. In fact, that very concept of interchangeable blowing surfaces or sources of blowing led to two patents at GTRI and two in-house programs to verify this novel concept. 
TANGENTIAL BLOWING OVER ROUNDED TRAILING EDGE SURFACE
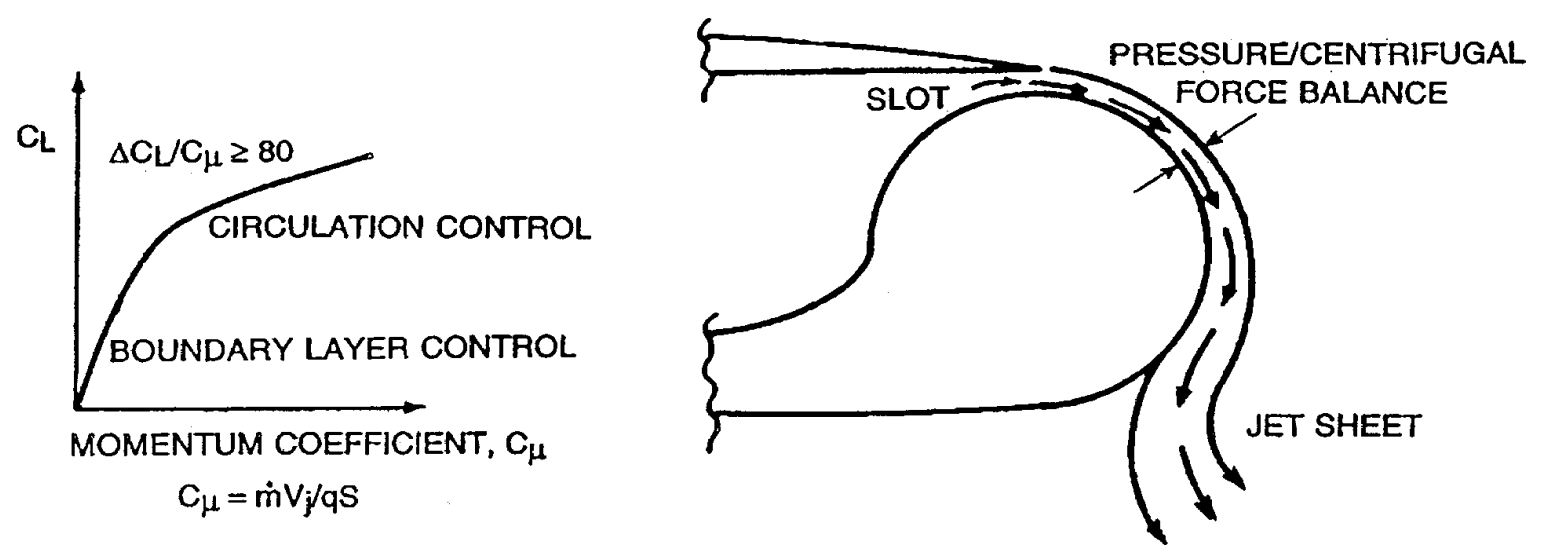

Figure 3. Basics of Circulation Control Aerodynamics on a Simple 2-Dimensional Airfoil
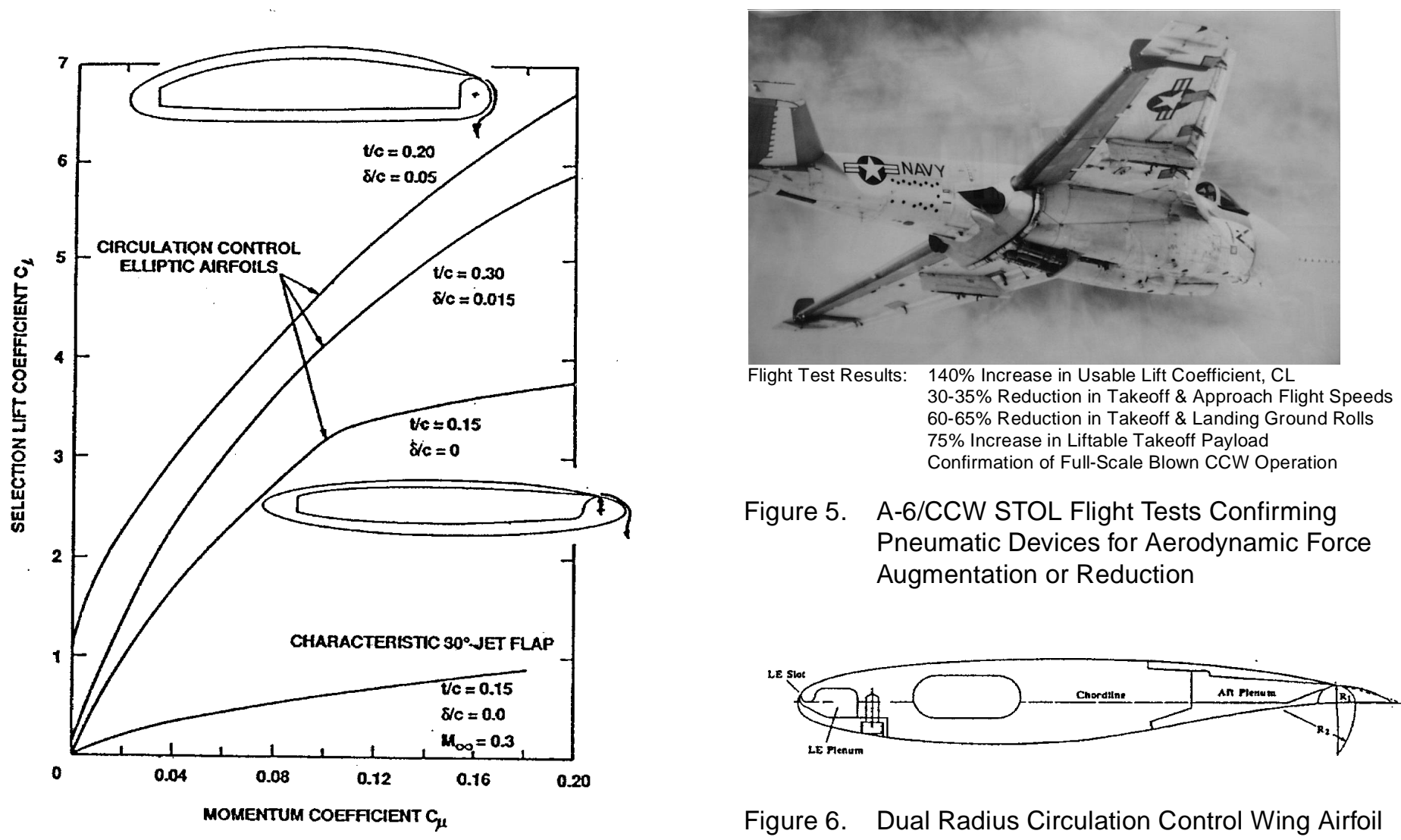

Figure 5. A-6/CCW STOL Flight Tests Confirming Pneumatic Devices for Aerodynamic Force Augmentation or Reduction

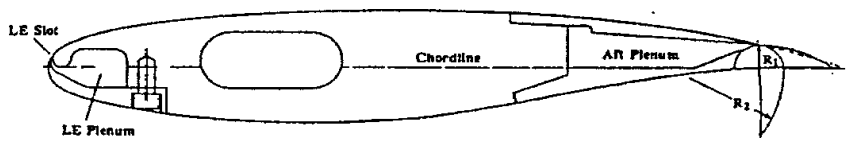

Figure 6. Dual Radius Circulation Control Wing Airfoil

Figure 4. Typical Blown Lift Generating Capabilities of Simple Two-Dimensional Circulation Control Elliptic Airfoils at $\alpha=0^{\circ}$ 


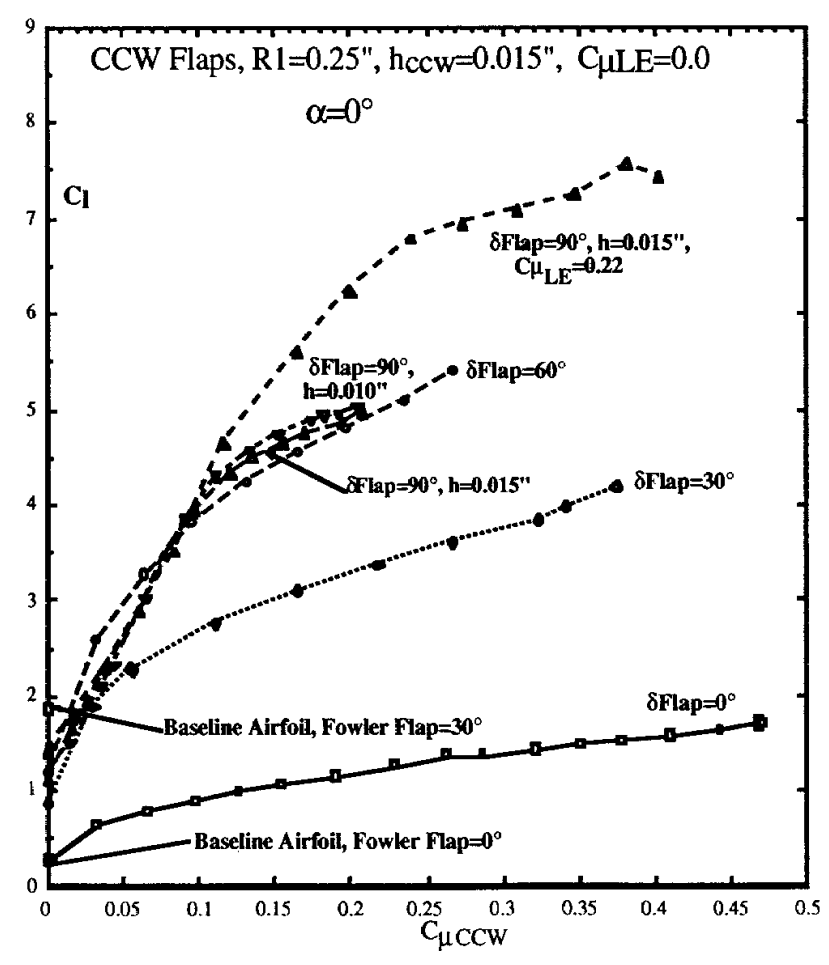

Figure 7. Lift Variation with Blowing for the Dual Radius 2-Dimensional Circulation Control Wing Airfoil at $\alpha=0^{\circ}$

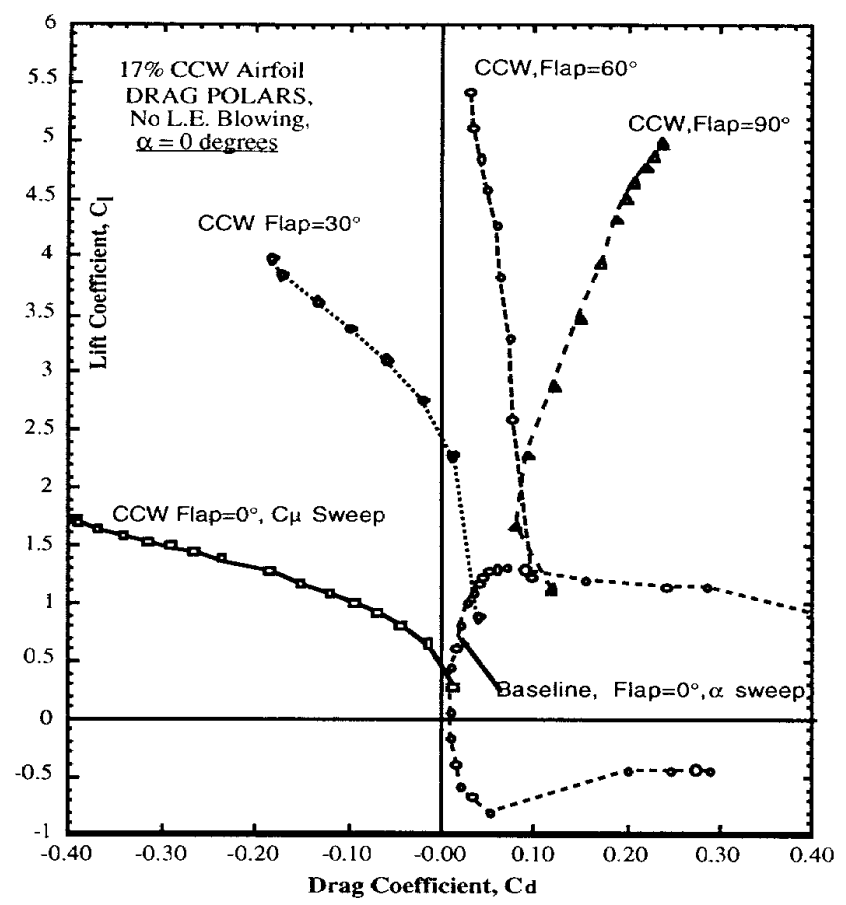

Figure 8. Lift/Drag Polars with Blowing for the Dual Radius 2-Dimensional CCW Airfoil at $\alpha=0^{\circ}$

\section{PNEUMATIC APPLICATION TO A STREAMLINED AUTOMOBILE}

Figure 9 depicts a summary of aerodynamic problems likely to be experienced by even a streamlined automobile configuration. To address these, blowing was applied to the aft upper surface of a wind-tunnel model car, with the ability to segment the blowing slot from left to right across the span (Reference 3). Figure 10 shows the installation of this blown vehicle in the GTRI Model Test Facility subsonic research wind tunnel. Also seen is the blowing slot on the trunk of the car and a flow visualization tuft displaying the large degree of jet turning downstream of the slot. Design of the trailing edge geometry included the use of full 3-D Reynolds-averaged NavierStokes CFD solutions specifically modified for pneumatic blowing (Appendix A of Reference 3). Figure 11 shows measured drag coefficient change for two conditions: blowing of the full slot, and partial blowing only on the right side quarter slot. The full slot produces the large jet turning shown in Figure 10, and drag increases of greater than $70 \%$, showing potential for pneumatic aerodynamic braking. Blowing only the outside corner of the slot offsets corner vortex rollup and reduces drag by as much as $35 \%$, depending on configuration (refer back to Figure 1 for the corresponding fuel savings). In this case, we were also looking for, and confirmed, the changes in yawing and rolling moments produced by differential blowing. One can envision even greater reductions if the left side were also blown at the same time. Note that the addition of a simulated bumper to the mid aft plane of the car produced a lower drag level because the jet turned only until it impacted this bumper, produced a base pressure rise at this point, and then exited the vehicle heading downstream with some apparent thrust recovery to further offset drag. Figure 12 shows lift change with blowing for the same configurations. Blowing the full aft slot yields a lift increase of $170 \%$, with increases of over $100 \%$ occurring at $\mathrm{C}_{\mu}=0.2$ (an internal plenum blowing pressure of only $5 \mathrm{psig}$ ); the quarter slot yields less lift because turning is restricted to only the outboard segment. The bumper again restricts turning and thus restricts lift. One can again envision a similar slot appliedto the lower surface that could yield negative lift or positive down force instead. This concept has been patented by GTRI and actually verified by a similar lower surface installation on a model of a European Formula 1 race car shown in Figure 13 (results are of course proprietary). Note that the inverted conventional high-lift wings with flaps normally employed for down force are absent here. 
GOAL: Apply Aerodynamic Blowing Techniques to a Streamlined Automobile Configuration to Improve its Aerodynamic and Stability Characteristics

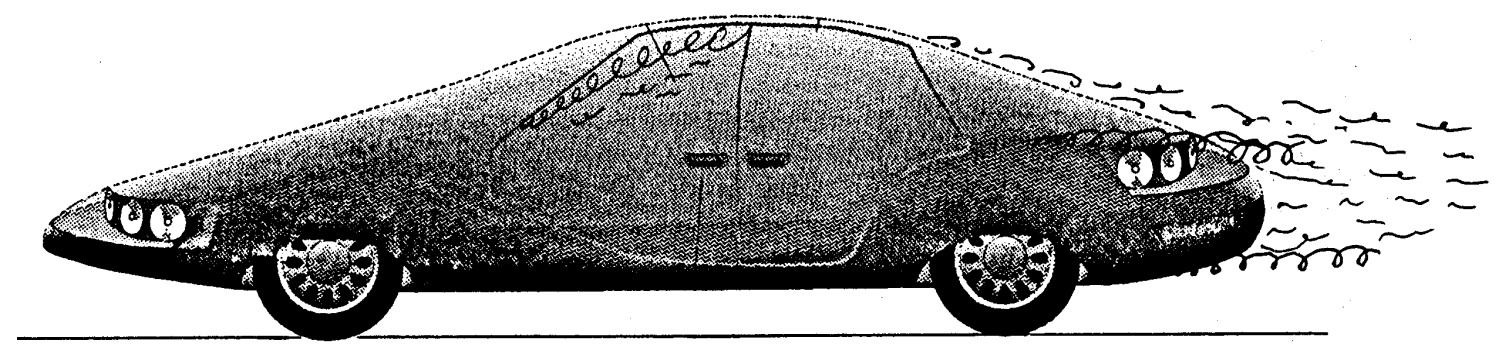

TYPICAL AERODYNAMIC PROBLEM AREAS FOR AUTOMOBILES:

- DRAG CAUSED BY FLOW SEPARATION AND VORTEX FORMATION

- NOISE CAUSED BY FLOW SEPARATION AND VORTEX FORMATION

- DIRECTIONAL SENSITIVITY \& INSTABILITY CAUSED BY YAW, SIDE FORCES \& GUSTS

- POWER CONSUMPTION BY PROPOSED DRAG REDUCTION DEVICES \& CONTROLS

- EXCESSIVE UPPER SURFACE LIFT--INCREASED DOWNLOAD REQUIRED UNIQUE SOLUTION: MULTI-PURPOSE APPLICATIONS OF PNEUMATIC (BLOWN) AERODYNAMIC TECHNOLOGY

Figure 9. GTRI FutureCar In-House Pneumatic Aerodynamics Project
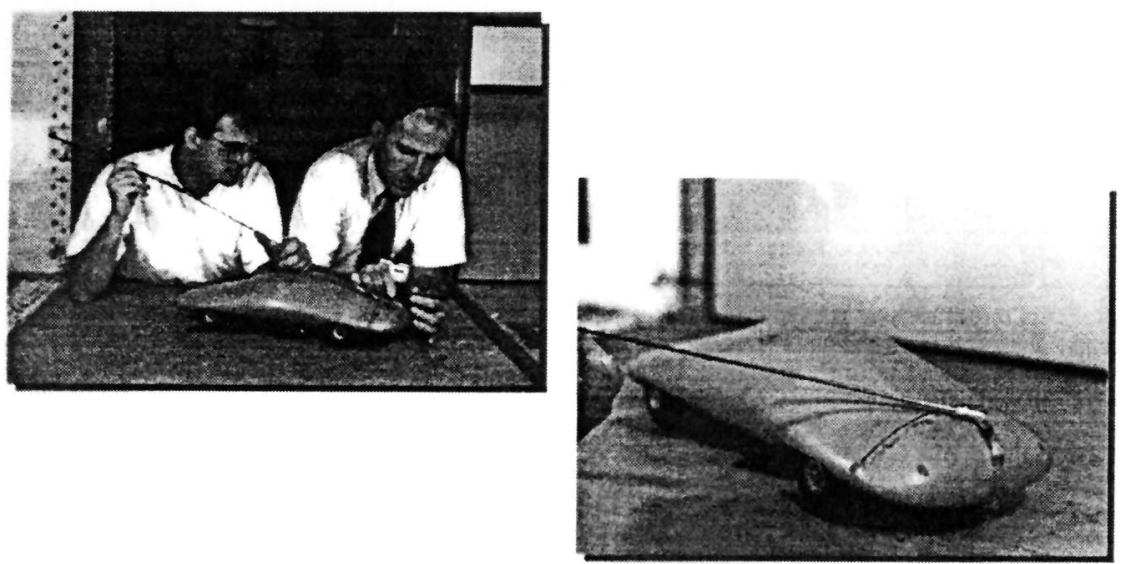

Figure 10. Experimental Confirmation of Blown Jet Turning Showing Pneumatic Technology on a Streamlined Car at GTRI 


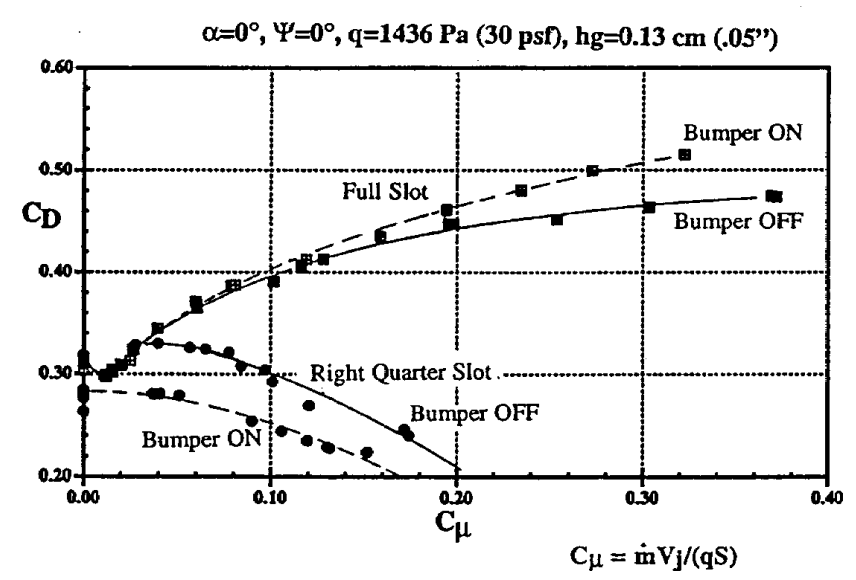

Figure 11. Effect of Blowing on Drag of Various Aft Configurations of the Streamlined Pneumatic Car Model at Yaw angle $=0^{\circ}$ and Pitch angle $=0^{\circ}$

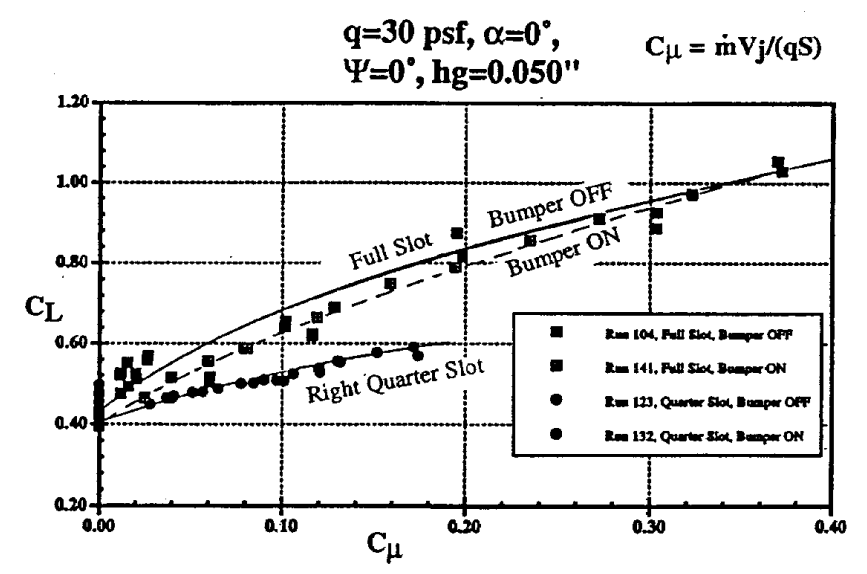

Figure 12. Effect of Blowing on Lift of Various Aft Configurations of the Streamlined Pneumatic Car Model at Yaw angle $=0^{\circ}$ and Pitch angle $=0^{\circ}$

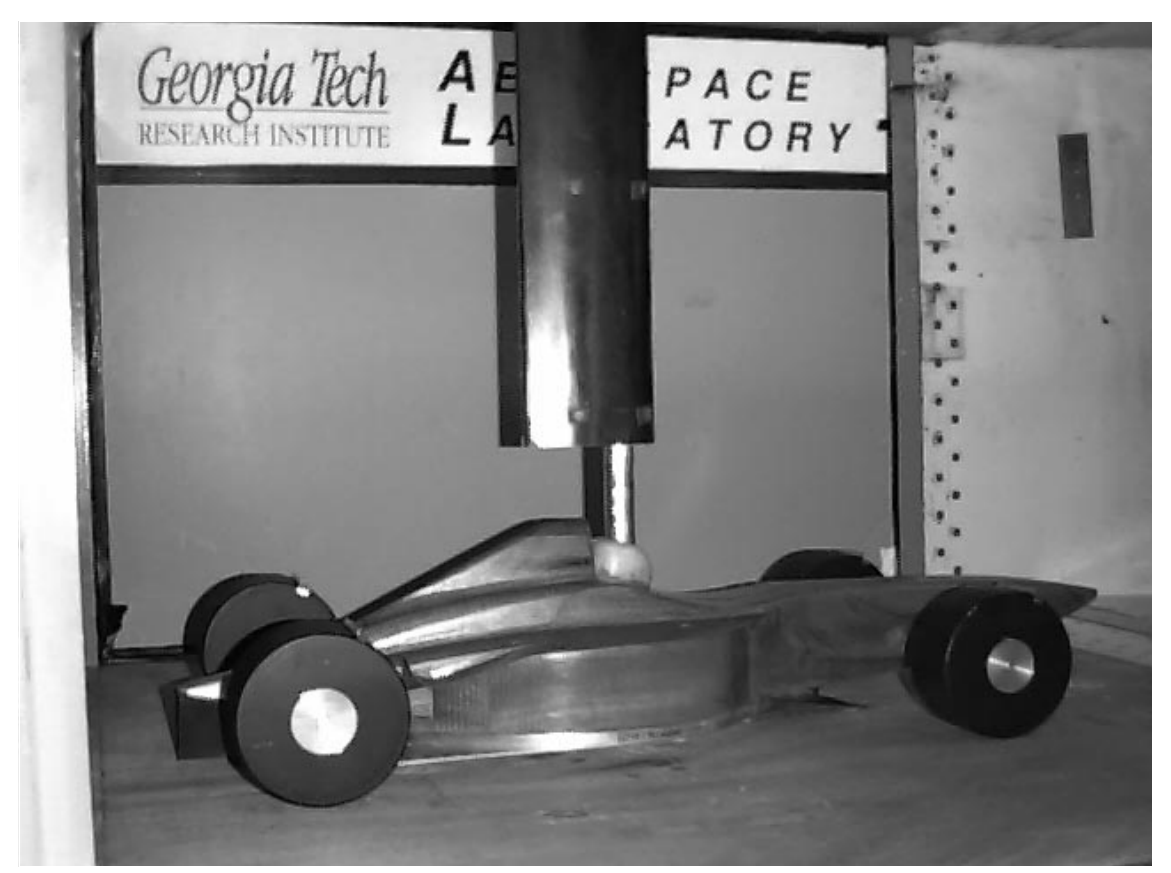

Figure 13. Pneumatic Formula 1 Race Car Model Installed in the GTRI MTF Tunnel

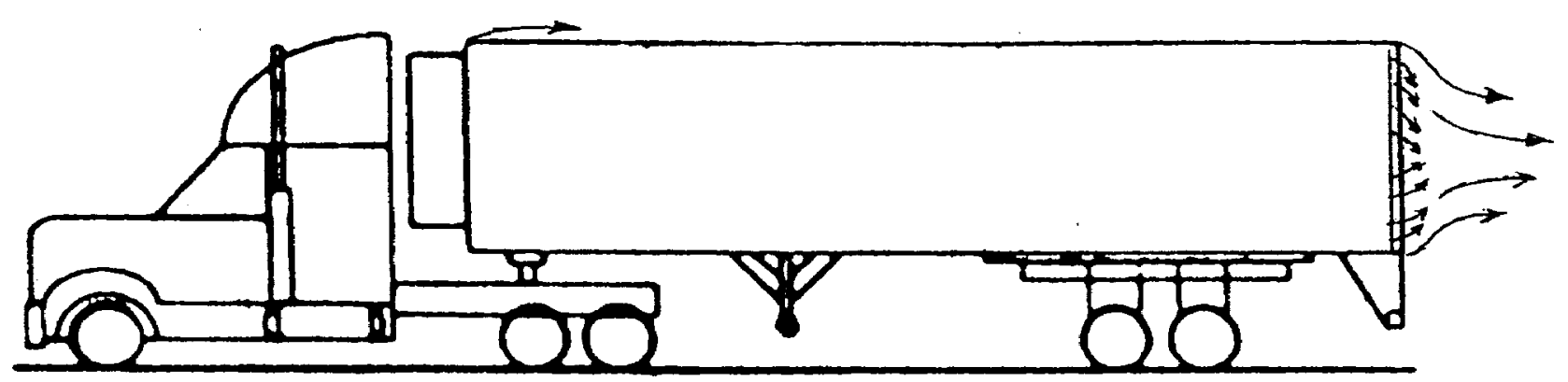

Figure 14. Application of GTRI Pneumatic Aerodynamic Technology to Heavy Vehicles, Showing 4 Aft Blowing Slots and Upper Leading-Edge Slot on Trailer 


\section{DOE PNEUMATIC HEAVY VEHICLE PROGRAM}

Based on the above results, a research program was funded at GTRI by Dr. Sidney Diamond of the Department of Energy's Office of Heavy Vehicle Technologies (Reference 4). The goal was to apply this pneumatic technology to tractor-trailer configurations to develop an appropriate experimental proof-of-concept evaluation that would hopefully lead to an on-the-road demonstration on an operating Heavy Vehicle. Portions of that effort, including a preliminary feasibility study, pneumatic Computational Fluid Dynamics (CFD) analyses, and design of baseline and pneumatic wind-tunnel configurations, have been completed and will be reported on in sections below.

FEASIBILITY STUDY; AERODYNAMICS - As an input to development of these pneumatic configurations in the basic feasibility study, a pneumatic aerodynamic database was necessary. It was felt that the streamlined automobile data from above and in Reference 3 would be inadequate because of the spanwise slot curvature and the highly streamlined car geometry, compared to an intended straight slot on the Heavy Vehicle trailer, and the 90-degree sharp corners on the bluff afterbody. The trailer configuration we wished to simulate is sketched in Figure 14: 4 aft blowing slots, one on each corner edge of the bluff afterbody, and a fifth slot at the top leading edge of the trailer. In combination, the aft blown slots could prevent separation and greatly reduce drag and water spray, while blowing only one slot could control the aerodynamic forces and moments on that side of the vehicle. The front slot would delay boundary layer buildup and flow separation, and could also be used to entrain flow up through the cab-trailer gap and thus enhance flow through the refrigerator unit frequently located there and sometimes blocked by the tractor aft side fairings.

It was felt that 2-dimensional pneumatic airfoil data would be more applicable here, and so the Dual Radius CCW airfoil of Figure 6 (Reference 7) was employed, with the flap deflected $90^{\circ}$ representing the aft roof corners on the trailer. To adapt the automobile convention of basing all aerodynamic coefficients on frontal area $(A)$ of the vehicle instead of on the airfoil planform area, the available 2$D$ data was converted to the trailer configuration by using the ratio of wing/frontal area, and thus the terms $C_{D A}$ and $\mathrm{C}_{\mu \mathrm{A}}$ in Figure 15. Notice that two different $90^{\circ}$ flaps are shown, with the slightly larger one producing a $C_{D A}$ reduction of almost $50 \%$ below the unblown value at a blowing coefficient of about 0.13 , before the drag begins to increase again with increased blowing.

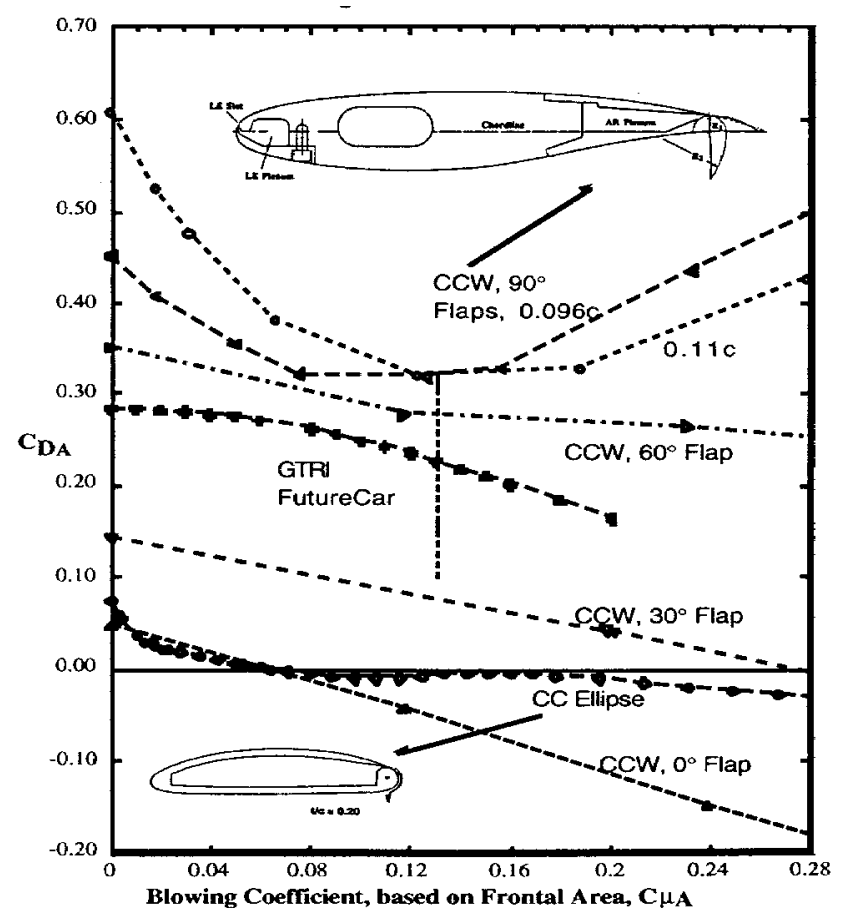

Figure 15. Drag Reduction with Blowing for a Family of Circulation Control Airfoils at $\alpha=0^{\circ}$ : Baseline for the Feasibility Study

FEASIBILITY STUDY; AIR SUPPLY SOURCES - A source of blowing air is necessary to produce the desired aerodynamic changes. Several possibilities exist: excess airflow from an existing turbocharger; a second turbocharger rotor added to an existing setup to supply only blowing air; engine exhaust pressure and mass flow; brake reservoir tanks; or an auxiliary compressor in or on the trailer. Discussions with current turbocharger manufacturers/suppliers provided turbo performance maps, but it was suggested that bleed of an existing turbo output could have some adverse effects on emissions and tuning without further mods to the unit. Thus, we calculated pressure and mass flows provided by a second turbo unit with various exit areas. Figures 16 and 17 show the predicted output weight flows and $\mathrm{C}_{\mu}$ for three duct exit diameters up to 3 inches, turbocharger exit total pressures $\left(\mathrm{P}_{\text {duct }}\right)$ up to approximately 45 psig (pressure ratio of approximately 4), and output temperature of $400^{\circ} \mathrm{F}$. Higher temperature produced somewhat lower weight flows at a constant pressure ratio, but yielded no change in $\mathrm{C}_{\mu}$. The output weight flow was converted to nondimensional $\mathrm{C}_{\mu}$ in Figure 17 by using a freestream dynamic pressure corresponding to $70 \mathrm{mph}$ highway speed and a truck frontal area of $A=107.5$ sq. ft. (height of $13.6 \mathrm{ft}$, width of $8.5 \mathrm{ft}$., less the area between the 
wheels). For comparison, data gathered from existing turbochargers showed outputs of 1.5 to $2 \mathrm{lbs} / \mathrm{sec}$ at 44 psig, while the possibility of using engine exhaust alone yields roughly the same weight flow but at a pressure around 1.5 psig. In summary, since using either exhaust alone or bleeding an existing turbo may interfere with engine tuning and exhaust emission levels, it may be more advisable to propose a second turbo added to the shaft of the first, or even an auxiliary turbo. Use of brake tank bleed is also a possibility, but it may raise a safety issue, and may be inadequate for continuous mass flow operation during highway driving. None the less, it appears that there are a number of reasonable sources to supply the required mass flow. That is complimented by CC being perhaps the most effective of all known blowing aerodynamic systems in terms of reduced $C_{\mu}$ required to produce a desired incremental aerodynamic force or moment.

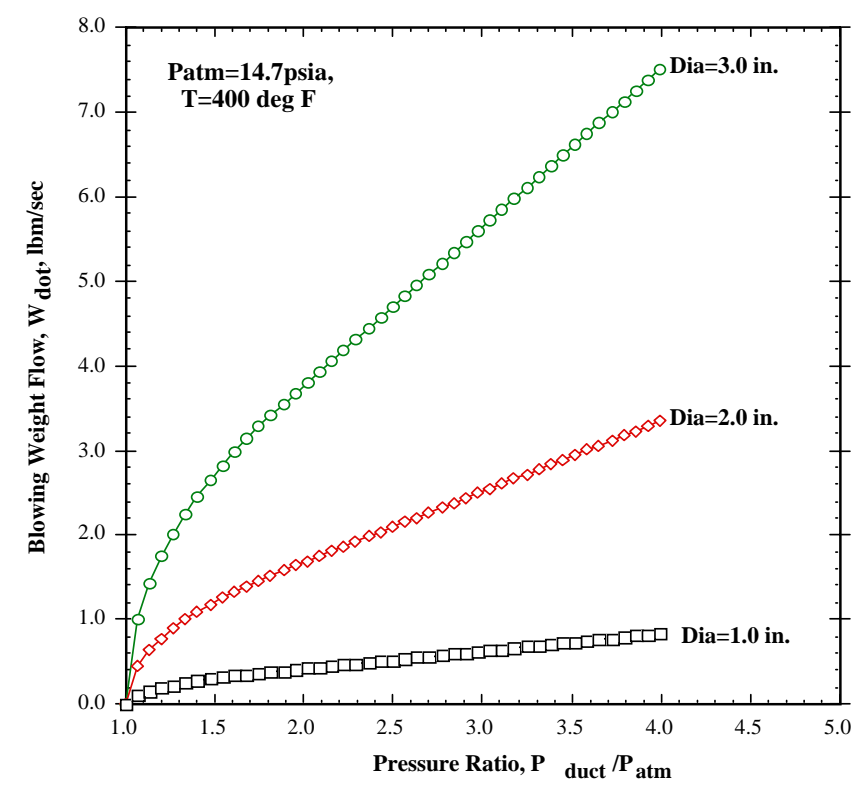

Figure 16. Isentropic Predictions of Turbocharger Output Weight Flow at $400^{\circ} \mathrm{F}$ Exhaust Temperature

FEASIBILITY STUDY; PNEUMATIC EFFECTIVENESS Predicted drag reduction from the available airflow is shown in Figure 18. Here, we've incorporated the CCW $90^{\circ}$ flap data from Figure 15, reduced to the truck frontal area, in a plot of required $\mathrm{C}_{\mu}$ to produce a given drag reduction, the upper dashed curve. This assumes that only one blowing slot on the trailer upper surface aft corner is operating, just like the airfoil. If the available air flow is split equally into two blowing slots, an upper and a lower, then drag reduction for the combined device should be even greater. This is because each blowing surface at only half the total $\mathrm{C}_{\mu}$ is now operating on that lesser $\mathrm{C}_{\mu}$ portion of the drag curve, where the reduction $\Delta \mathrm{C}_{\mathrm{D}} / \mathrm{C}_{\mu}$ is much greater. Thus, the lower dashed curve shows even greater drag reduction at the same total blowing, although it is suspected that these curves are somewhat optimistic and fail to take into account the trailing edge's geometric effects (i.e., very low aspect ratio and sharp corners). Nevertheless, both drag curves in Figure 18 show $\Delta C_{D} / C_{\mu}$ to be greater than $100 \%$ until the minima at the middle of the curves are reached.

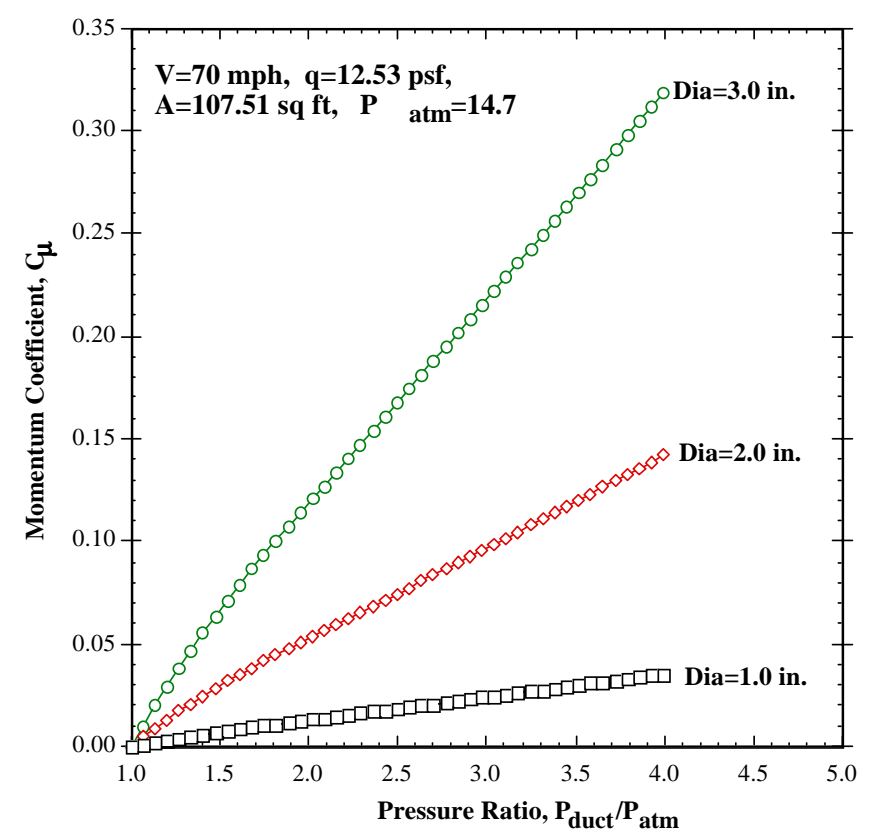

Figure 17. Predicted Blowing Momentum Coefficient Provide by Various Size Turbochargers Applied to a Typical Heavy Vehicle at $70 \mathrm{mph}$ Highway Speed

The right axis of Figure 18 is vehicle speed, and when combined with the available weight flows, pressures and jet velocities of the air sources from above, yield available $\mathrm{C}_{\mu}$, the solid curves. Where the dashed curves and the solid ones cross, the available momentum coefficient equals the required blowing, determining the greatest drag reduction that particular source can produce. From these approximations, drag reductions of over $50 \%$ seem to be quite possible, with even greater values likely depending on the performance of the combined slots.

The upcoming wind tunnel evaluations at GTRI will provide more accurate experimental data to allow better determination of the drag reductions, or increases if desired, from single and multiple slot configurations. 


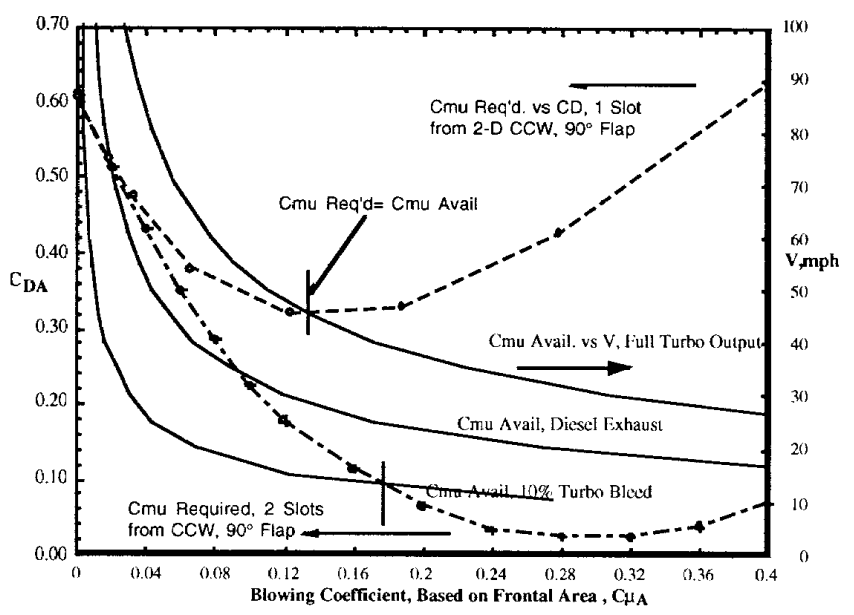

Figure 18. Sample Drag Variation with Blowing, and $\mathrm{C}_{\mu-}$ from Available Sources of Blowing at Variable Speeds

BASELINE HEAVY VEHICLE WIND TUNNEL MODEL A baseline model to act as a reference is required prior to the planned blowing tests, and as a basis upon which to build the pneumatic model configuration. A team of current researchers working for DOE on this problem has determined that an existing generic Heavy Vehicle configuration, the Ground Transportation Systems vehicle (Reference 8) will be quite appropriate. It is sketched in Figure 19, and is actually representative of a faired cabover-engine vehicle based on the Penske racing team's car carrier. As such, it becomes relatively independent of the numerous and varying cab roof fairings employed on a number of current Heavy Vehicles.

To be employed as an accurate wind-tunnel model, issues such as model size, wind tunnel blockage and test Reynolds number are important. Our model design was scaled to be compatible with the GTRI test section area of 1290 sq. in., and based on Reference 9 conditions, a physical blockage of 5 to 6 percent of tunnel area was desired, as well as reasonably high Reynolds number. Figure 19 shows that a 0.065 -scale model produces a blockage of $5.1 \%$ and Reynolds number based on trailer length of $1.90 \times 10^{6}$ for $\mathrm{V}=70 \mathrm{mph}$, or $3.90 \times 10^{6}$ at maximum tunnel speed. GTRI's dimensions were incorporated into the Figure 19 design, and fabricated by prototype shop Novatek Inc into the model of Figure 20. Here, a number of parameters are variable, including $\mathrm{cab} /$ trailer gap, cab height, a removable gap, trailer leading-edge radius, wheels on/off, vehicle height above the road (floor) and yaw angle between the tractor and trailer, Figure 20. The model will be mounted on a single strut, which is hollow and will later be used as the blowing air supply route into the model. This strut will mount on a six-component floor balance below the tunnel floor, which can also be yawed and raised vertically to vary ground clearance height. The test setup will be very similar to that described in Reference 3 for the blown streamlined car test program. Particle imaging laser velocimeter data will be used to quantify the flowfield characteristics aft of the vehicle.

PNEUMATIC DEVICE DESIGN - A visit to Great Dane Trailers in Savannah GA allowed measurement of trailer geometry and discussion of blown system applications with trailer manufacturers. Figure 21 shows different geometries and door headers between a swinging door and a rolling door design, with the rolling door providing more room around the header. It is proposed to test and evaluate a number of pneumatic device geometries similar to those shown in this figure, with the trailing edge radius determining both the fit with the header and the degree of jet turning that can be supported. Note that the blowing plenum can easily fit into the area of the current rain channel, at least on a demonstrator configuration. These configurations are currently being designed for the pneumatic portion of the tunnel test program to evaluate their performance relative to each other and to the conventional configuration shown here.

FEASIBILITY STUDY; PERFORMANCE - To evaluate the effects on performance which can be produced by the above pneumatic changes in aerodynamic lift and drag, calculations of required power were done for a range of highway speeds. Figure 22 shows the results for a hypothetical 65,000 pound 18-wheel tractor-trailer rig with a frontal area of $107.5 \mathrm{sq}$. ft. traveling over flat highway at sea level. Three cases are considered: a conventional rig with $C_{D}=0.80$; a pneumatic rig showing a $35 \%$ drag reduction (i.e., the pneumatic streamlined car's drag reduction levels); and a pneumatic rig with a $50 \%$ drag reduction (from Figure 18). This produces the three "Aerodynamic" horsepower required curves, where drag force $\mathrm{D}=\mathrm{C}_{\mathrm{D}} \mathrm{q} A$, and $\mathrm{HP}_{\text {req'd }}=\mathrm{DV} / 550$. Thus the required aerodynamic horsepower reduces in the same proportion as the drag coefficient, i.e., 35 to $50 \%$ at a given speed. Also included here is horsepower required to overcome rolling resistance of the tires, which is directly proportional to effective weight on the wheels times the tire friction coefficient, taken here to be 0.015 . For the conventional rig, the HP to overcome rolling resistance is linear with velocity. For the blown configurations, lift is assumed to vary with blowing available and speed squared, so the effective weight of the vehicle reduces as the lift increases with speed. The upper curves are the total horsepower required at the wheels (exclusive of gearing and internal engine losses). For these cases, at a sample speed of $70 \mathrm{mph}$, the power required for the conventional rig to overcome drag plus rolling resistance can be reduced $24 \%$ by the lesser pneumatic configuration and $32 \%$ by the more effective one. If fuel savings are reduced proportionally, these numbers indicate considerable increase in cruise efficiency for these blown vehicles. The amount of actual drag reduction and or lift augmentation will be determined from the upcoming blown wind tunnel tests. 
GTRI 0.065-Scale Wind-Tunnel Model and Variables

Full Scale: $W=8.5^{\prime}, H=13.5^{\prime}, L_{T R A I L E R}=48^{\prime}, L_{R I G}=>65^{\prime}, V=70 \mathrm{mph}, \operatorname{Re}_{T I r}=29.56 \times 10^{\wedge} 6$

\begin{tabular}{|c|c|c|c|c|c|c|c|}
\hline \multirow[t]{2}{*}{ Blockage } & $\underline{\text { W,in. }}$. & $\underline{H}$, in. & Scale & $\underline{L}_{\text {Trailer, in. }}$ & $\underline{L}_{\text {Rig, in. }}$ & \multicolumn{2}{|c|}{$\underline{\operatorname{Re}}_{\text {Trailer }} / 10^{* *} 6$} \\
\hline & & & & & & (V=70mph) & $q=50 p s f)$ \\
\hline 0.10 & 9.31 & 14.79 & .0913 & 52.59 & 71.21 & 2.67 & 5.48 \\
\hline 0.08 & 8.33 & 13.23 & .0816 & 47.00 & 63.65 & 2.39 & 4.90 \\
\hline 0.06 & 7.21 & 11.46 & .0707 & 40.72 & 55.15 & 2.07 & 4.25 \\
\hline 0.051 & 6.63 & 10.53 & .0650 & 37.44 & 50.70 & 1.90 & 3.90 \\
\hline 0.05 & 6.58 & 10.46 & .0645 & 37.15 & 50.31 & 1.89 & 3.87 \\
\hline 0.04 & 5.89 & 9.35 & .0577 & 33.24 & 45.01 & 1.69 & 3.47 \\
\hline
\end{tabular}

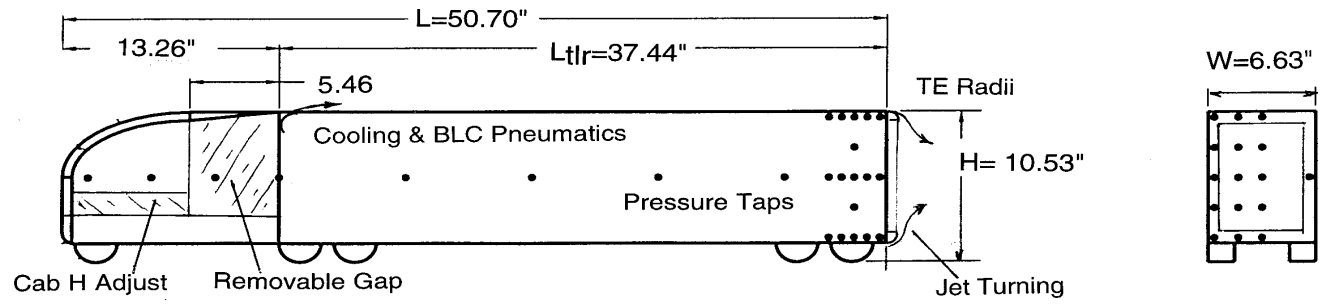

Figure 19. Design and Scaling of Pneumatic Heavy Vehicle Model based on GTS Model.

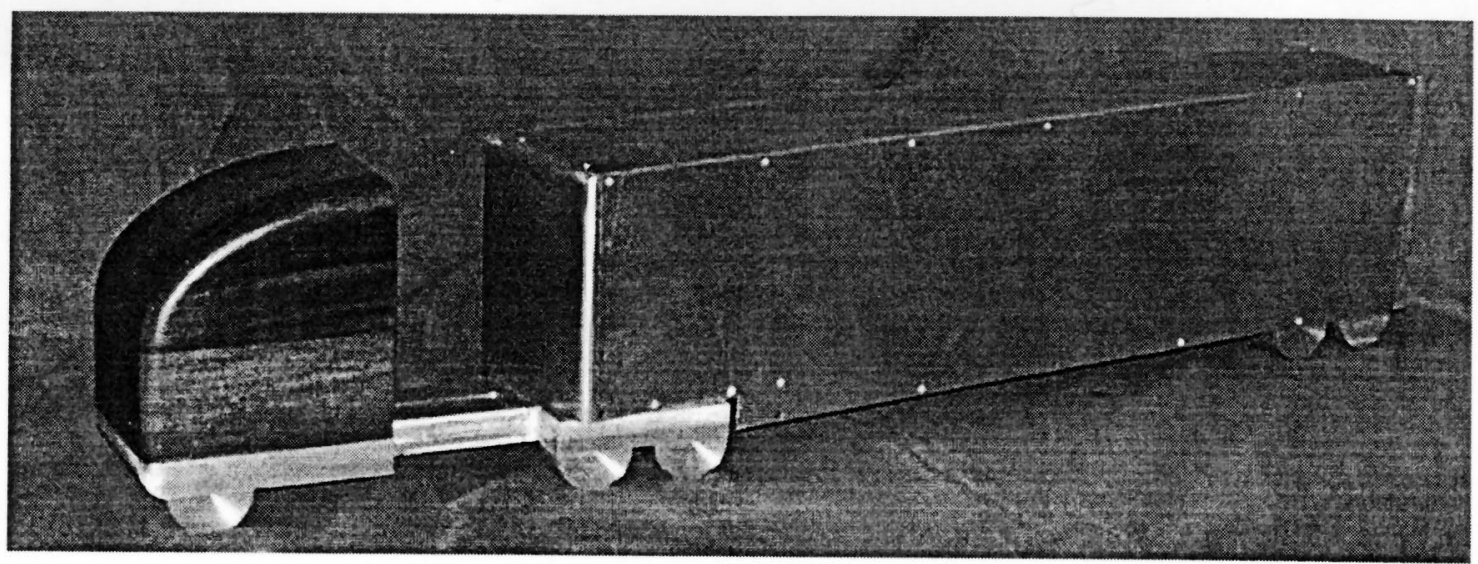

Full-Height Tractor and Yawed Trailer

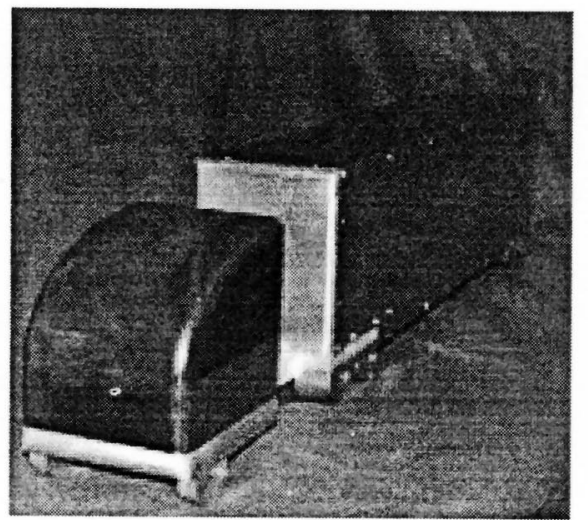

Shorter-Height Tractor, Unyawed Trailer

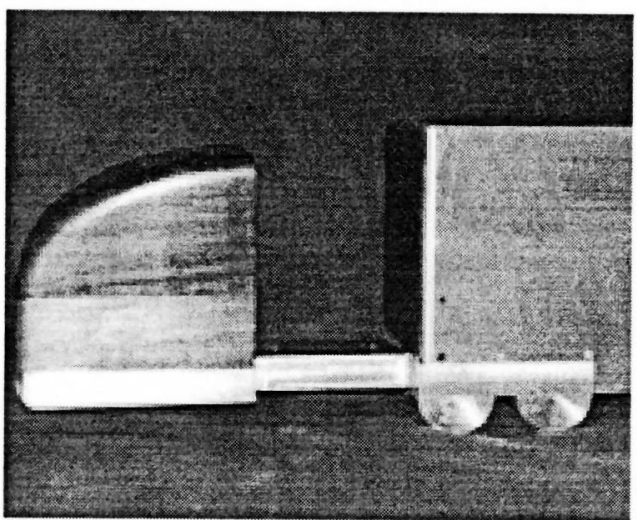

Front Wheels Removed

Figure 20. GTRI 0.065-Scale Wind Tunnel Model with Various Configurations 


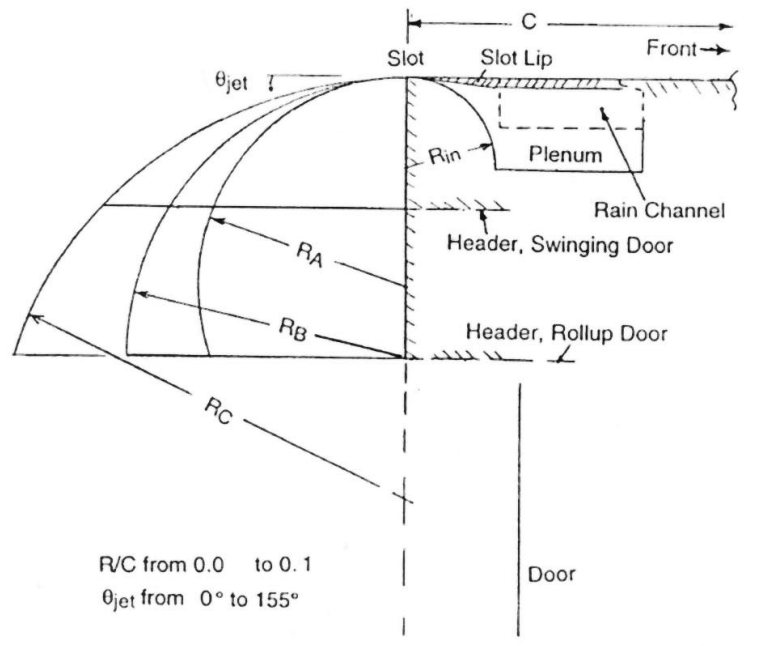

Candidate Pneumatic Trailing Edge Geometries

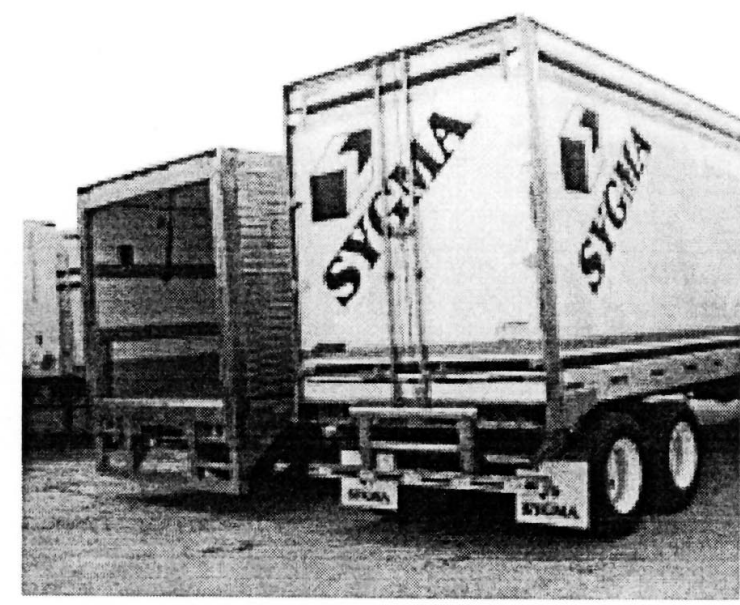

Typical Great Dane Trailer Door Designs

Figure 21. GTRI Trailing Edge Designs for the Pneumatic Configurations

CFD FLOW PREDICTIONS - As part of the design study, numerical Computational Fluid Dynamics analyses were performed at the Georgia Tech School of Aerospace Engineering by Dr. Marilyn Smith and graduate student researchers. Using algorithms based on Reynolds-averaged Navier-Stokes equations modified for pneumatic applications, (see Reference 3), both unblown and blown flowfield characteristics were predicted for the Heavy Vehicle configurations. Figure 23 shows a sample specially-contoured CFD grid fit at the centerline of the upper aft surface of the trailer, including the rounded corner and tangential slot location. Figure 24 presents the severe turbulence and separated flow demonstrated by the streamtraces generated behind the unblown configuration. Even with the rounded corner, large separation is prevalent. Figure 25 shows the streamtraces as blowing is increased to $C_{\mu}=0.019$ and 0.056 , based on a $70 \mathrm{mph}$ velocity. Here, the streamtraces smoothly attach to the curved corners of the aft face, with much reduced separation and turbulence well around the corner and down the door face. These flow patterns clearly emphasize the flow re-attachment capabilities of pneumatic configurations and the potential for drag reduction.

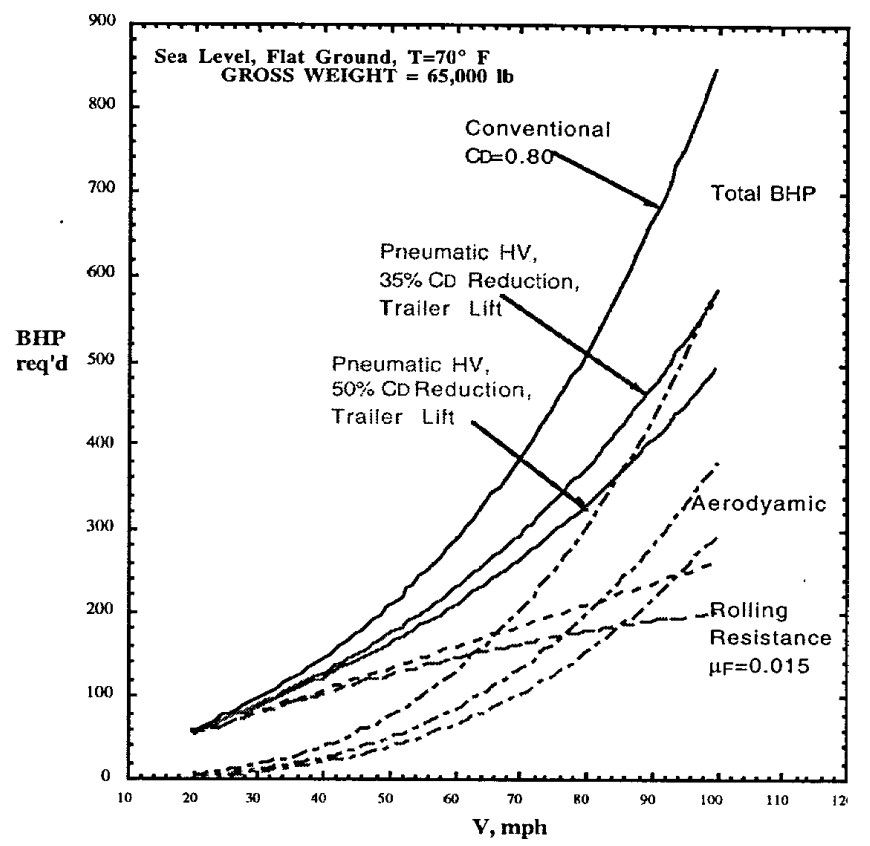

Figure 22. Comparative Power Reductions for Drag and Rolling Resistance due to Pneumatics 


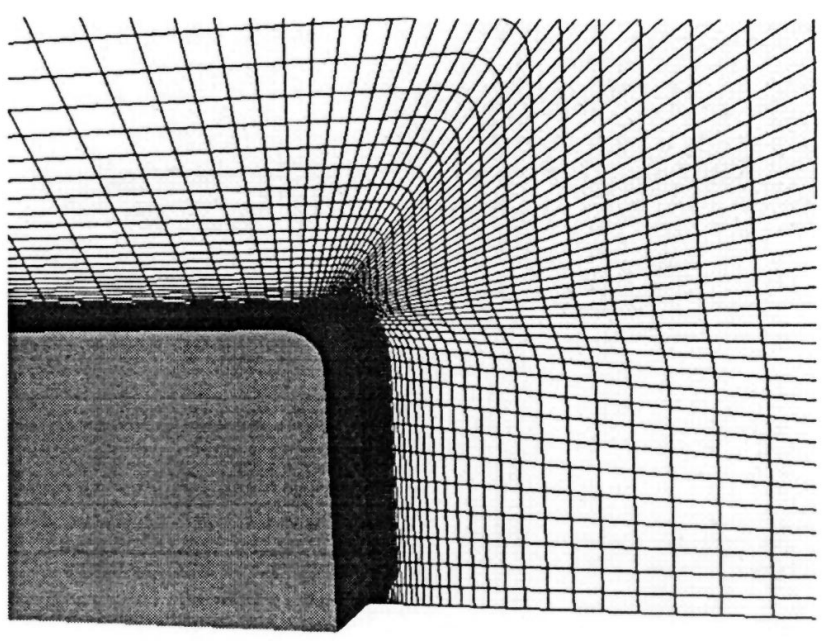

Figure 23. Sample CFD Grid Employed

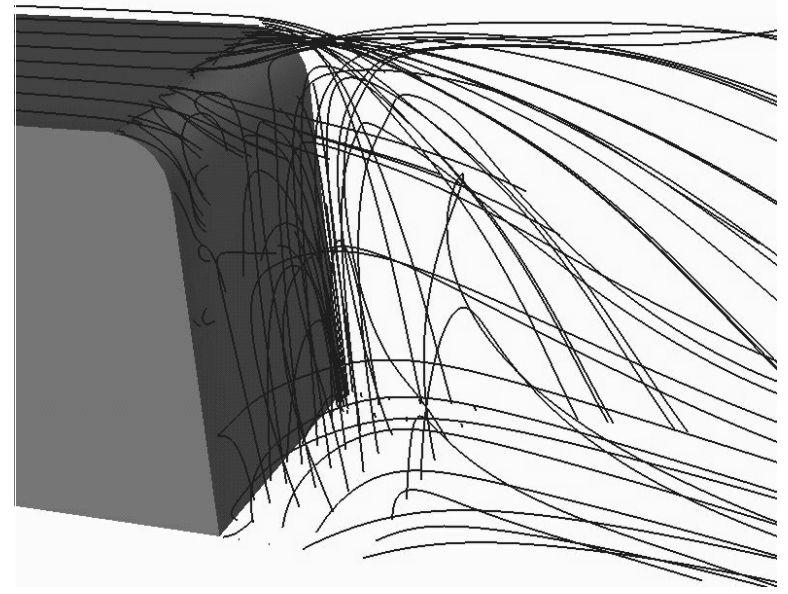

Figure 24. CFD Prediction of Flow over Unblown Trailer Aft Face, Showing Large Separated Flow Regions

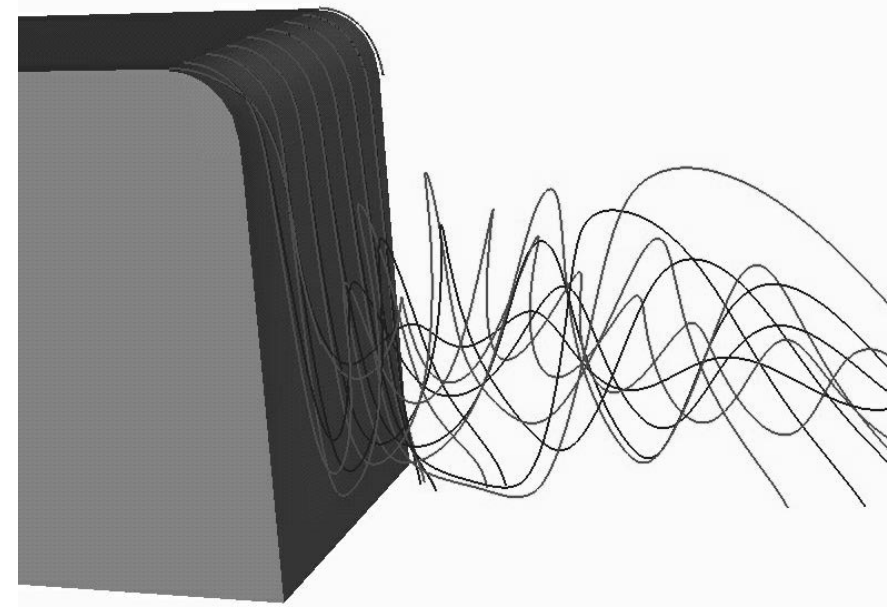

Figure 25. CFD Prediction of Flow over Blown Trailer Aft Face, $\mathrm{C} \mu=0.019$, and $\mathrm{C} \mu=0.056$

\section{CONCLUSIONS}

The initial stages have been completed of a research program being conducted for the DOE Office of Heavy Vehicle Technologies to develop, evaluate, and apply pneumatic aerodynamic devices to improve the performance, economy, and safety of operation of Heavy Vehicles. Based on a number of experimental pneumatic aerodynamic data bases and on pneumatic CFD calculations, an initial feasibility study has been conducted to investigate the application of a pneumatic system to an on-the-road Heavy Vehicle demonstrator and predict potential performance gains. On streamlined cars, measured drag showed reductions of $35 \%$ or increases of over $100 \%$ when desired, and lift or download increases of over $170 \%$ were recorded.

These results can be combined with experimental data bases for pneumatic airfoils. These data sources have lead to predictions of greater than $50 \%$ drag reduction on tractor/trailer configurations using one or more blowing slots and similar large drag increases for braking, plus variable lift or download of at least those values experienced on the pneumatic car model. Prediction of on-theroad performance of a pneumatic Heavy Vehicle using blown drag reduction coupled with lift-enhanced reduced rolling resistance suggests that these aerodynamic improvements can result in $24 \%$ to $32 \%$ reductions in horsepower required to overcome drag and tire resistance. The potential of pneumatic aerodynamic devices applied to Heavy Vehicles can be summarized as:

- Pneumatic devices on back of trailer, blowing slots on all sides and/or front top can yield:

- Aerodynamic control of all three forces and all three moments plus boundary layer control

- Separation control and base pressure recovery = drag reduction, or Base suction = drag increase

- Leading-edge (LE) suction on trailer = drag \& turbulence reduction

- Additional lift for rolling resistance reduction ( $\mathrm{F}_{\text {Rolling }}=\mu \mathrm{N}$, where $\mathrm{N}=\mathrm{Wt}$ - Lift $)$, or Reduced lift (increased download) for traction, braking and reduced hydroplaning

- Blowing locations instantaneously switchable

- Partial slot blowing or differential blowing for roll control \& lateral stability

- One-side blowing (LE or TE) for yaw control \& directional stability

- No moving parts, small component drag

- Very short aft addition = no length limitation

- Splash, Spray \& Turbulence reduction

- Use of existing on-board compressed air sources (exhaust, turbocharger, brake tank)

- Advanced Pneumatic Cooling Systems

- Safety of Operation 
Since one of the tasks of the current program is to disseminate research findings and results to the Heavy Vehicle industry and to future potential manufacturers and users of this technology, we submit / present this technical paper in that light.

\section{RECOMMENDATIONS}

To further develop the concept of pneumatic vehicles, the above conclusions suggest that we conduct:

- Continued analyses of pneumatic improvements and design of a full-scale test configuration

- Further study of available air supplies and any penalties associated with blowing

Whereas a portion of this is expected to be accomplished in the remaining effort of the current DOE program, it is further recommended that a follow-on full-scale on-theroad demonstration of typical freight-hauling runs using pneumatics be conducted in comparison with a baseline representative conventional Heavy Vehicle. This proofof-concept comparison should verify or modify our conclusions above; the expected results of that program would be:

- Dramatic improvement in aerodynamic performance, efficiency, stability, and control of large commercial Heavy Vehicles

- Non-moving external components = all-pneumatic systems and components

- Fast response and augmented forces = safety of operation

- Control of all aerodynamic forces and moments by the same pneumatic system using existing onboard air sources, which are driver or system controlled

- For safety and stability, make positive use of aerodynamic components not currently employed (lift, download, side force, yaw, roll) in Heavy Vehicle operation, and use increased drag for braking

- Very small-size aft trailer extension; small or no front or top add-ons

\section{ACKNOWLEDGMENTS}

The author wishes to acknowledge Dr. Sidney Diamond, Dr. Jules Routbort and Mr. Richard Wares of DOE OHVT for their continued support and encouragement, as well as Mr. Victor Suski for the continued very valuable involvement of ATA. The technical assistance of Mr. Ken Burdges of Novatek Inc. in wind-tunnel model design and fabrication is also greatly appreciated, as are the CFD analyses of Dr. Marilyn Smith and graduate students of the Georgia Tech School of Aerospace Engineering.

\section{REFERENCES}

1. Hucho, Wolf-Heinrich, Editor, "Aerodynamics of Road Vehicles, from Fluid Mechanics to Vehicle Engineering," Butterworth-Heinemann, London, 1990.

2. Suski, Victor, "Improved Heavy Truck Aerodynamics, Statement of Need," American Trucking Associations, Alexandria, VA, 1995

3. Englar, R. J., M. J. Smith, C. S. Niebur and S. D. Gregory, "Development of Pneumatic Aerodynamic Concepts for Control of Lift, Drag, and Moments plus Lateral/Directional Stability of Automotive Vehicles," SAE paper 960673 , presented at SAE International Congress \& Exposition, Detroit, Feb. 26-29, 1996. Also published in SAE SP-1145, "Vehicle Aerodynamics: Wind Tunnels, CFD, Aeroacoustics, and Ground Transportation Systems," pp. 27-38.

4. U. S. Department of Energy, Oak Ridge National Laboratory, "Development and Evaluation of Pneumatic Aerodynamic Devices to Improve the Performance, Economics, Stability and Safety of Heavy Vehicles, Contract No. 450000555, Dec 1, 1998.

5. Englar, R. J. and C. A. Applegate, "Circulation Control-A Bibliography of DTNSRDC Research and Selected Outside References (Jan 1969 to Dec 1983)," David Taylor Naval Ship Research and Development Center Report 84/052, Carderock, MD, Sept., 1984

6. Englar, Robert J., "Development of the A-6/ Circulation Control Wing Flight Demonstrator Aircraft," DTNSRDC Report ASED-274, January 1979; and Englar, R. J,. et al, "Design of the Circulation Control Wing STOL Demonstrator Aircraft," AIAA paper No. 79-1842, August 1979

7. Englar, R. J., et al., "Application of Circulation Control to Advanced Subsonic Transport Aircraft," AIAA Journal of Aircraft, Vol. 31, No. 5, pp. 1160-1177, Sept Oct, 1994

8. Gutierrez, W. T., B. Hassan, R.H. Croll, and W.H. Rutledge, "Aerodynamics Overview of the Ground Transportation Systems (GTS) Project for Heavy Vehicle Drag Reduction," SAE Paper 960906, 1996.

9. SAE Information Report J2085, "Aerodynamic Testing of Road Vehicles; Closed-Test-Section Wind Tunnel Boundary Interference," August 1993. Also published as "Closed-Test-Section Wind Tunnel Blockage Corrections for Road Vehicles," SP-1176, February 1996.

\section{CONTACT}

Robert J. Englar, Principal Research Engineer Georgia Tech Research Institute

Aerospace, Transportation \& Advanced Systems Lab

Aerodynamics \& Acoustics Branch

Atlanta, GA 30332-0844

(770) 528-3222

(770) 528-7586, Wind tunnel

(770) 528-7077 Fax

bob.englar@gtri.gatech.edu 